\title{
Increase of Lifetime and Screening Results by Advanced Hardfacing Technologies
}

\author{
Jens Laskowski \\ Welding Alloys GmbH \\ Ostring, Wachtendonk, Germany \\ jens.laskowski@welding-alloys.com
}

\begin{abstract}
The presentation "Increase of lifetime and screening results by advanced hardfacing technologies" shows results of trials with new hardfacing technologies and their effect on the lifetime on screening systems. On site tests with customer plants under real conditions show the coherence of hardfacing and constant screening results. Preliminary to the trials, a few basic principles of hardfacing and abrasion will be explained and shown to allow a better classification of the outcomes of the tests.

Although these tests have been made exemplarily in a sintering plant, they can be easily generalized for every screening/sieving application in every industry.
\end{abstract}

Keywords: screens, hardfacing, abrasion, wear protection, lifetime, grain size, sustainability

\section{Introduction}

In the process chain of mining and refining it is a necessity to screen out the usable bulk from the one who has to go through the re-processing. As most screened particles are abrasive, as for example sinter, cement, coal, ore, etc..., the screening decks are extremely stressed parts in a critical production step, if they fail or leak too many 'false' parts, this would have a direct effect on the end product.

The trials made in this article aim for the goal to increase the lifetime of the cut passages, as these are the bottleneck and quality affecting parts of the screens.

\section{Principles of Abrasion and Hardfacing}

To help understanding the effect of hardfacing on the lifetime of the screens and to clear up the misconception that hardness has anything to do with the lifetime and durability of the screens, the basics of the interaction between abrasion and hardfacing will be examined. It is vital to see the relation to the parts to increase the lifetime by choosing the ideal hardfacing and processing of it.

\subsection{Abrasion}

The wear phenomen on screening decks is generally described as 'low abrasion', classified as the particles are rubbing/sliding on the surface[1]. As the pressure from these abrasives is very low, they don't change size and maintain their geometric structure. For this reason, the carbide structure of the hardfacing has to be as orthogonal as possible to the flow direction.

\subsection{Hardfacing}

Having a low abrasion performance of the bulk, the carbide structure has to be as orthogonal as possible towards the flow direction with small, needle sharped carbides. The following pictures help to describe the desired effect; the reduction of the sliver size by giving the abrasive particle the minimal attack surface. 


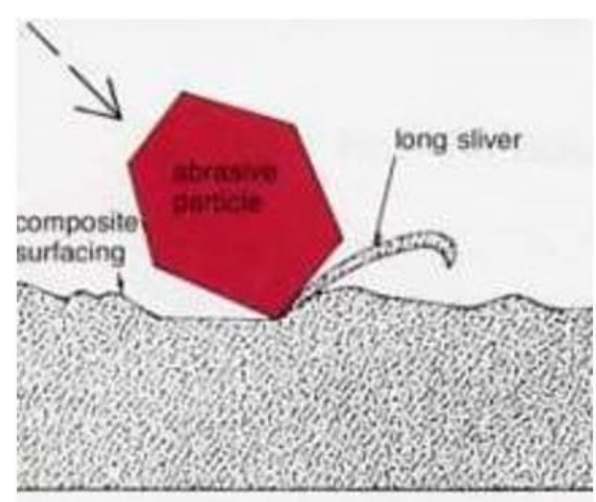

steel base

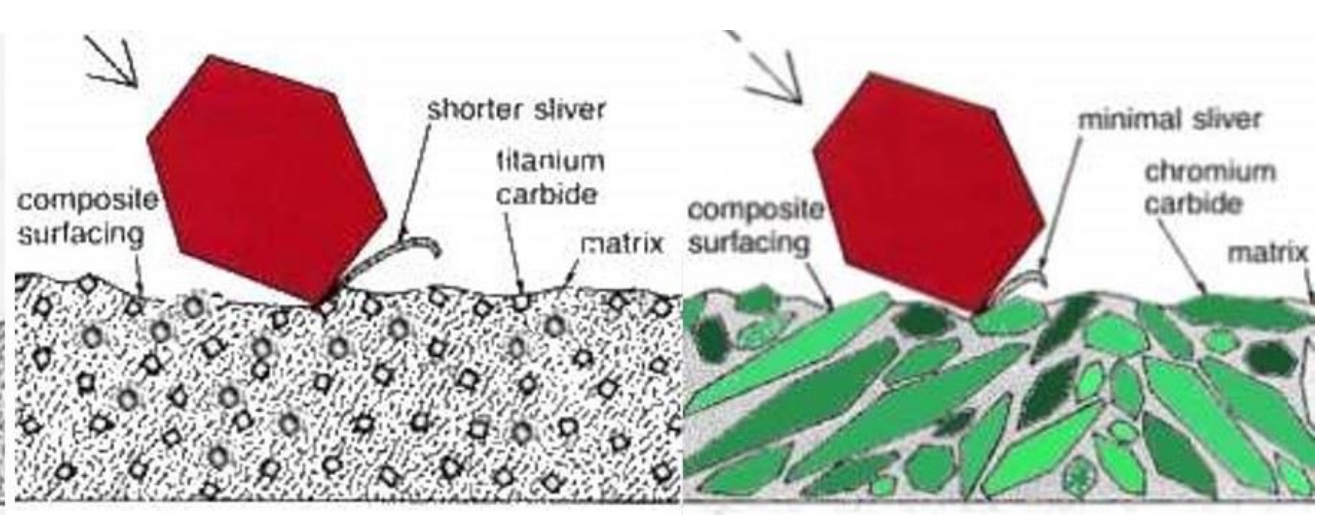

steel base steel base

Fig. 1: Abrasion behaviour on different carbides.

As seen above, a vertical orientation of the carbides with less free space in the matrix is the best condition against abrasive wear. The intermediate spaces between the carbides could be even more reduced by alloying secondary carbide creators like Niobium etc.

Another critical part of hardfaced screens is the structure of rifts. As a high chromium/high carbon overlay is applied on a mild steel grade, the congelation/cooling behaviour is different. The resulting intergranular tension releases itselfs in rifts, usually orthogonal towards the welding direction. These cracks have an unpredictable penetration depth and position, if the hardfacing is applied without controlling the rifts, it is very likely to have the tension build up and then depressurized in one massive crack down to the base material, reducing the overall integrity of the screen.

As this happens also in the passage of the screens, it tears off the geometry of the screening hole, reducing the usability in a very short time.

\subsection{Conclusion on Abrasion and Hardfacing}

It is vital for the hardfaced plates to have a very smooth hardfacing, especially the overlap of the welding beads, as these are potential predetermined breaking points[2]. In addition, it is mandatory to focus on controlled stress relief cracks to avoid an early fringing of the screening holes. An example of correspondingly welded plates is shown under Fig.2.

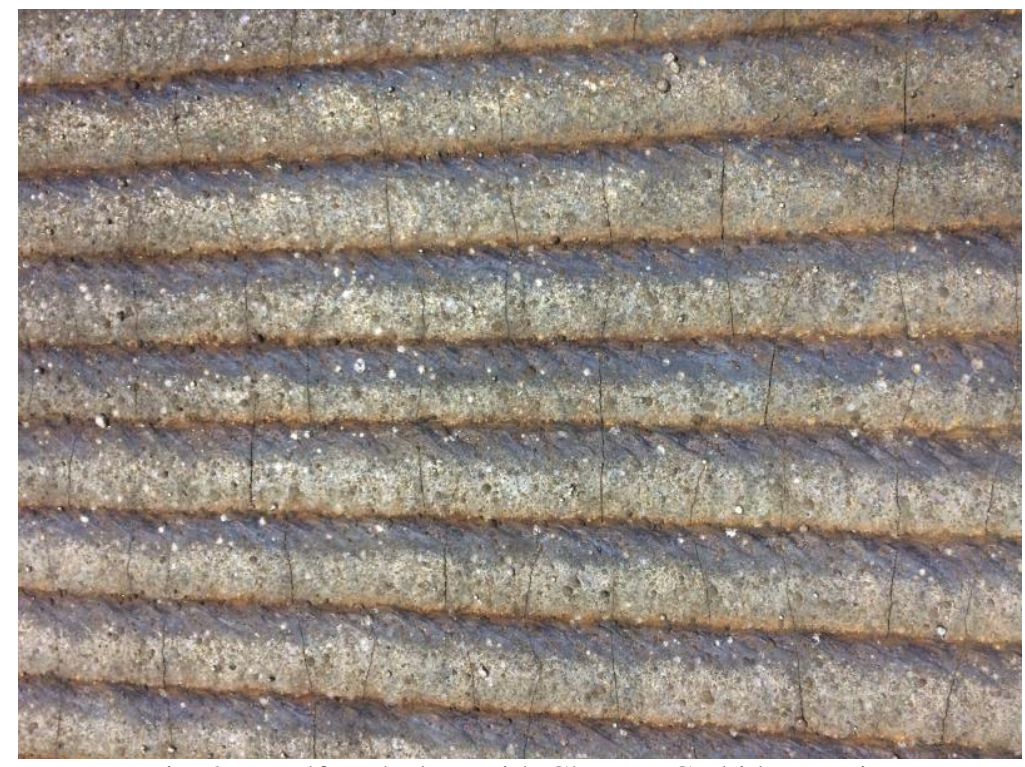

Fig. 2: Hardfaced Plate with Chrome-Carbide-Matrix. 


\section{Field Experiences}

The above described criteria have been put to a direct comparison with 'common' manufactured hardfaced screens. It has to be mentioned, that the standard plate has been purchased from a different supplier. All suppliers had the same specification and scope of supply.

The requested plates consisted of $10 \mathrm{~mm}$ base material S355 and 10mm hardfacing, specified as "Abrasodur A45-O"; according to DIN8555: 1-MF-10.2-60-GP. The chemical analysis of the reference is: C:5.3; Cr:21.0; Mo:6.3; Nb:6.0; $\mathrm{W}: 1.9 ; \mathrm{V}: 1.0 ; \mathrm{Fe}:$ Bal.

The holes had a pear-geometry with $\varnothing_{\max }: 40 \mathrm{~mm}$ and $\varnothing_{\min }: 26 \mathrm{~mm}$ and were cut conical with an opening of $1 \mathrm{~mm}$ per $10 \mathrm{~mm}$ thickness.

\subsection{Testing Enviroment}

The test took place in a sintering plant in Germany. The screens have been assembled in the first row after the bulk discharge (most wear in this row) on a Schenk Process machine. The daily tonnage of processed sinter over this screening deck is approx. 10.000 tons/day at max. $150{ }^{\circ} \mathrm{C}$.

All screens have been assembled on March $10^{\text {th }} 2016$.

\subsection{Observations}

The standard plates had to be replaced after 16 weeks. The hardfacing was still intact, it has been reduced by $2-3 \mathrm{~mm}$ in an average. The reason for the replacement has been the lack of geometry, the holes fringed out and didn't screen correctly (comp. Fig.3).

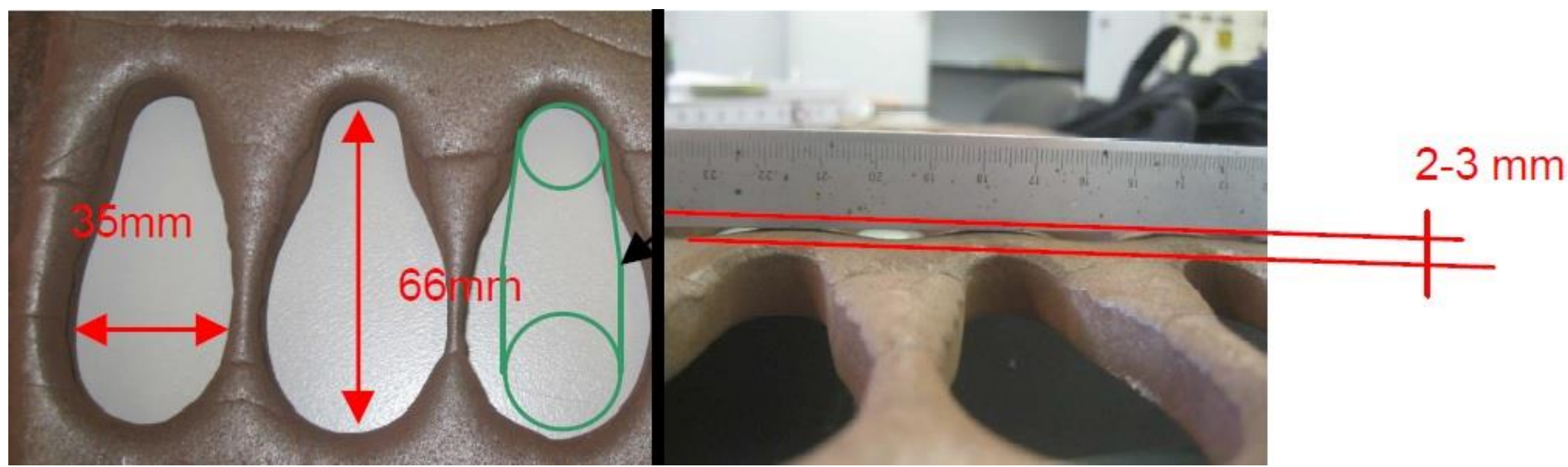

Fig. 3: Standard hardfaced screens after 16 weeks.

The screens with the advanced manufacturing method have been reduced in thickness by the same amount but kept the geometry of the original pear. After 30 weeks of operation the plates have been dismantled during a block-shutdown which has been scheduled in advance to execute maintenance operations on the entire screening machine. Even after 30 weeks, the screen-geometry was still in better condition than the standard plates after 16 weeks (see Fig.4). Subsequent tests showed an average lifetime of 38 weeks. 


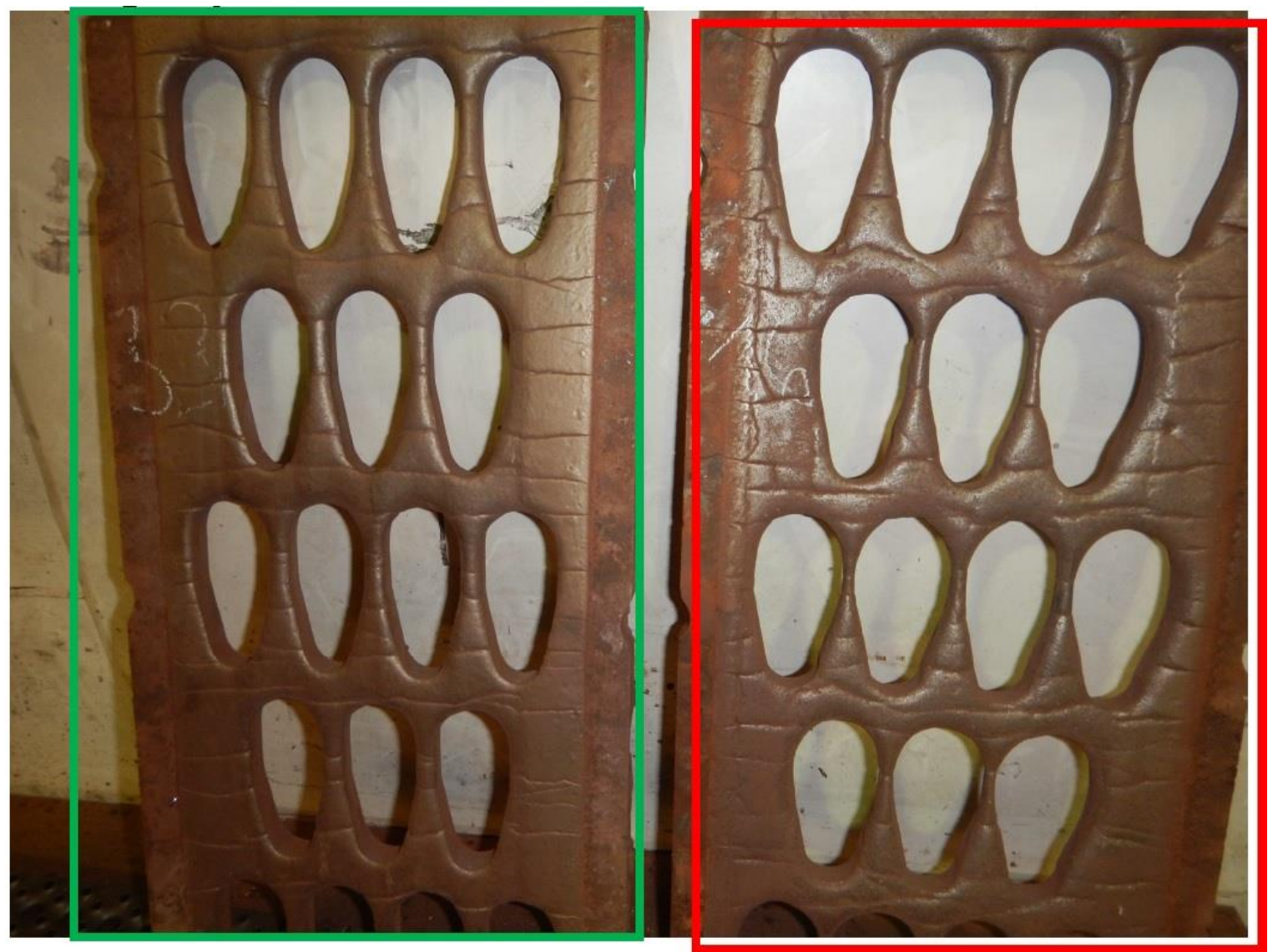

Fig. 4: Comparison: Advanced Plates (left/green/30weeks) <-> Standard Plates (right/red/weeks).

\section{Conclusion}

Having taken a closer look at the way the hardfacing is applied than its pure chemical composition and hardness it has an sweeping impact on the lifetime of the screens and the quality of the bulk material. The cost difference for the standard and advanced plates is minimal, as it is the procedure and not the material that is changed, but the performance difference is unmissable.

Therefore, it is mandatory to specify the way the hardfacing is applied instead of only prescribing the chemical composition and requested hardness. This results in a cost cutting by over 50\%, as only half the screens are needed per year and one shutdown becomes redundant, reducing costs and maximizing the plant availability.

\section{Acknowledgements}

The author would like to express his gratitude towards Helena Herzog and Dr. Gerd Peters for inspiration and support.

\section{References}

[1] H. Uetz, Abrasion und Erosion. Carl Hanser Verlag München, 1986.

[2] H. S. Yune, "Surface and Coatings Technology," vol. 58, no. 1, pp. 73-77, 1993. 